\title{
Impact of two early treatment protocols for anterior dental crossbite on children's quality of life
}

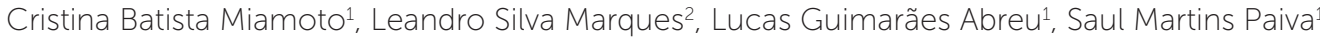

DOI: https://doi.org/10.1590/2177-6709.23.1.071-078.oar

Objective: To assess the impact of two early treatment protocols for anterior dental crossbite on children's quality of life. Methods: Thirty children, 8 to 10 years of age, with anterior dental crossbite, participated in this study. Individuals were divided into two groups: Group $1-15$ children undergoing treatment with an upper removable appliance with digital springs; Group $2-15$ children undergoing treatment with resin-reinforced glass ionomer cement bite pads on the lower first molars. Quality of life was evaluated using the Brazilian version of the Child Perceptions Questionnaire $\left(\mathrm{CPQ}_{8-10}\right)$, which contains four subscales: oral symptoms $(\mathrm{OS})$, functional limitations (FL), emotional well-being $(\mathrm{EW})$, and social well-being $(\mathrm{SW})$. A higher score denotes a greater negative impact on children's quality of life. Children answered the questionnaire before treatment $\left(\mathrm{T}_{1}\right)$ and twelve months after orthodontic treatment onset $\left(\mathrm{T}_{2}\right)$. Descriptive statistics, the Wilcoxon test and analysis of covariance (ANCOVA) were performed. Results: Children's mean age was $9.07 \pm 0.79$ years in Group 1 and $9.00 \pm 0.84$ years in Group 2. For Group 1, the FL and EW subscale scores and the overall $\mathrm{CPQ}_{8-10}$ were significantly higher in $\mathrm{T}_{1}$ as compared to $\mathrm{T}_{2}$ ( $p=0.004, p=0.012$ and $p=0.015$, respectively). For Group 2 , there were no statistically significant differences. The ANCOVA showed no significant difference regarding quality of life at $\mathrm{T}_{2}$ between groups, after controlling for quality of life measures at $\mathrm{T}_{1}$. Conclusions: The difference regarding the impact on quality of life between groups is not related to the protocol used.

Keywords: Children. Malocclusion. Anterior crossbite. Interceptive orthodontics. Quality of life.

Objetivo: avaliar o impacto de dois protocolos de tratamento precoce para a mordida cruzada anterior dentária na qualidade de vida de crianças. Métodos: trinta crianças de 8 a 10 anos de idade com mordida cruzada anterior dentária participaram desse estudo. Os indivíduos foram divididos em dois grupos: Grupo $1-15$ crianças em tratamento com aparelho removível superior com molas digitais; Grupo 2 - 15 crianças em tratamento com batentes de cimento de ionômero de vidro resinoso nos primeiros molares permanentes inferiores. A qualidade de vida foi avaliada por meio da versão brasileira do Child Perceptions Questionnaire $\left(\mathrm{CPQ}_{8-10}\right)$, o qual contém quatro subescalas: sintomas bucais $(\mathrm{SB})$, limitações funcionais (LF), bem-estar emocional (BE) e bem-estar social (BS). Um escore mais alto indica um impacto mais negativo na qualidade de vida. As crianças responderam ao questionário antes do tratamento $\left(T_{1}\right)$ e 12 meses após o início do tratamento ortodôntico $\left(T_{2}\right)$. Estatística descritiva, o teste Wilcoxon e análise de covariância (ANCOVA) foram realizados. Resultados: a média de idade das crianças foi de 9,07 $\pm 0,79$

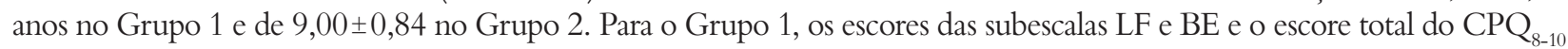
foram significativamente maiores em $\mathrm{T}_{1}$ do que em $\mathrm{T}_{2}$ ( $p=0,004, p=0,012 \mathrm{e} p=0,015$, respectivamente). Para o Grupo 2, não houve diferença estatisticamente significativa. A ANCOVA não mostrou diferença significativa entre os grupos em relação à qualidade de vida em $\mathrm{T}_{2}$, após o controle para as medidas de qualidade de vida em $\mathrm{T}_{1}$. Conclusões: a diferença em relação ao impacto na qualidade de vida entre os grupos não foi relacionada ao protocolo de tratamento utilizado.

Palavras-chave: Crianças. Má oclusão. Mordida cruzada anterior. Ortodontia interceptativa. Qualidade de vida.

${ }^{1}$ Universidade Federal de Minas Gerais, Departamento de Odontopediatria e Ortodontia (Belo Horizonte/MG, Brazil).

${ }^{2}$ Universidade Federal dos Vales do Jequitinhonha e Mucuri, Departamento de Odontopediatria e Ortodontia (Diamantina/MG, Brazil).

» The authors report no commercial, proprietary or financial interest in the products or companies described in this article.
How to cite: Miamoto CB, Marques LS, Abreu LG, Paiva SM. Impact of two early treatment protocols for anterior dental crossbite on children's quality of life. Dental Press J Orthod. 2018 Jan-Feb;23(1):71-8. DOI: https://doi.org/10.1590/2177-6709.23.1.071-078.oar

Submitted: April 19, 2017 - Revised and accepted: September 10, 2017

Contact address: Lucas Guimarães Abreu

Rua Maranhão 1447 / 1101, Funcionários, Belo Horizonte/MG, Brasil CEP: 30.150-338 - E-mail: lucasgabreu@bol.com.br 


\section{INTRODUCTION}

The concept of oral health-related quality of life (OHRQoL) has been used to measure the impact of oral outcomes on the functions and quality of life of individuals. ${ }^{1}$ Recently, one of the objectives of dental research has been to assess the OHRQoL of children and adolescents, since oral diseases, such as dental caries and malocclusion, have a negative effect on the physical and psychological well-being of young people., ${ }^{2,3}$ Generally, the instruments used to assess OHRQoL are constructed in the form of surveys consisting of questions aimed at measuring how much oral outcomes affect people's lives and daily routines by means of responses organized in numerical scales. ${ }^{4}$

Anterior dental crossbite occurs when there is a change in the inclination of one or more anterior teeth with the upper incisor(s) positioned palatally in relation to the lingual surface of the lower teeth. ${ }^{5}$ Studies evaluating these changes reported the possibility of periodontal problems in the lower incisors, the presence of discomfort, alteration in the anteroposterior position of the mandible, and problems with the temporomandibular joint (TMJ), when the problem is not treated early. ${ }^{6,7}$ Interceptive orthodontic intervention in the mixed dentition allows the orthodontist to correct the anterior crossbite earlier in a way that promotes the harmonious growth of the bone bases, ${ }^{8,9}$ mitigating the chances of severe disorders in the permanent dentition.

The impact of orthodontic treatment with fixed appliances on the quality of life of children and adolescents has been explored in depth in prior literature. ${ }^{10,11}$ However, the association between interceptive orthodontic treatment and OHRQoL still needs to be properly investigated. ${ }^{12,13}$ It is important to consider relevant aspects of the patient's quality of life during orthodontic treatment, such as potential psychosocial problems and functional disabilities caused by the wearing of orthodontic devices. ${ }^{14}$ Therefore, the objective of this study was to assess the impact of two early treatment protocols for correction of the anterior dental crossbite (upper removable appliance with digital springs; and resin-reinforced glass ionomer cement bite pads on the lower first molars) on the quality of life of children. The null hypothesis was that there is no difference between both protocols regarding the impact on children's quality of life.

\section{METHODS}

\section{Participants, study site, and eligibility criteria}

The sample of this prospective study was selected from the registry of patients attending the Children's Clinic of the Federal University of the Valleys of Jequitinhonha and Mucuri (UFVJM), located in the city of Diamantina, Brazil. The study was conducted between March, 2014 and December, 2015. Individuals between 8 and 10 years of age and who presented anterior dental crossbite in the mixed dentition, with the presence of the four first permanent molars and at least one crossed permanent incisor, were included in this study. Exclusion criteria were: (I) impairment in general health based on medical history and physical examination, (II) anterior skeletal or functional crossbite, (III) posterior crossbite associated with anterior crossbite, (IV) presence of sucking habits or individuals who had stopped the habit less than a year before the study's onset, $(\mathrm{V})$ previous history of orthodontic treatment, and (VI) individuals with any oral disease or those who had undergone any kind of dental treatment within the last month.

The sample consisted of 30 individuals, 8 to 10 years of age, with anterior dental crossbite in the mixed dentition. The participants were divided into two groups: Group 1 consisted of 15 patients undergoing treatment with an upper removable appliance with digital springs; Group 2 consisted of 15 patients undergoing treatment with resin-reinforced glass ionomer cement bite pads on the lower first molars. The distribution of 30 individuals between the two groups was performed randomly as follows: an envelope was prepared with 30 records with the names of the two treatment protocols, each mode containing 15 records. A card was selected from the envelope for each participant, indicating the group to which he/she belonged. This process was carried out by an assistant.

\section{Ethical considerations}

The research proposal was submitted to and approved by the Ethics Committee on Human Research from UFVJM (protocol \#525.056). Children and their guardians were informed about the study and that their participation was entirely voluntary. The children who agreed to participate in the study signed an informed consent form, as did their parents 
or guardians. After the follow-up period, patients whose anterior dental crossbite had not been fully corrected continued the treatment or were subjected to a new type of therapy.

\section{OHRQoL assessment tool}

Participants' OHRQoL was assessed by means of the Brazilian version of the Child Perceptions Questionnaire $\left(\mathrm{CPQ}_{8-10}\right)$, which is a tool used to assess the impact of oral conditions on the quality of life of children from 8 to 10 years of age. ${ }^{15}$ The $\mathrm{CPQ}_{8-10}$ consists of 25 questions divided into four subscales: oral symptoms (OS), with 5 questions; functional limitations (FL), with 5 questions; emotional well-being (EW), with 5 questions; and social well-being (SW), with 10 questions. An ordinal scale provides the following response options for each question: never (0), once/twice (1), sometimes (2), often (3), and every day/almost every day (4). The scores for each subscale are computed by adding up the scores for each question. The overall score is calculated by adding the scores of the four subscales. The overall score ranges from 0 to 100 points. Higher values indicate a more negative impact of the oral outcome on children's quality of life. The $\mathrm{CPQ}_{8-10}$ was translated and adapted cross-culturally for the Brazilian population with similar psychometric properties to the original version. ${ }^{16}$

Data were collected through surveys that were answered in an average time of 15 minutes in a separate room next door to the clinic. The subjects answered them on two occasions: the first occurred before placing the two types of protocols, for determining the baseline $\left(\mathrm{T}_{1}\right)$; the second assessment was carried out twelve months after the onset of the interceptive orthodontic treatment $\left(\mathrm{T}_{2}\right)$. Treatments were conducted by a specialist in orthodontics, who stressed the benefit of the early treatment of anterior dental crossbite for the children and their parents/caregivers. Shortly after the placement of the resin-reinforced glass ionomer cement bite pads or the upper removable appliance with digital springs, the participants and their parents/caregivers were given instruction on diet restrictions, hygiene, and the commitment required by orthodontic treatment. This information was emphasized again on subsequent monthly appointments. Parents/caregivers were asked to check their own commitments before scheduling consultations for their children, to avoid delays or missing the consultations. A telephone number was provided in case of need for emergency consultation due to breakage or loss of devices.

\section{Early orthodontic protocols for anterior dental crossbite}

\section{Upper removable appliance with digital springs}

The device presented two Adams clasps in the permanent upper first molars, two arrow clasps between the deciduous upper molars and a double spring adapted to the palatal surfaces of the teeth to be uncrossed, in addition to the vestibular arch (Fig 1). The posterior region presented an occlusal splint in an attempt to promote sufficient disocclusion, enabling the movement of the crossed teeth. The patients were advised to remove the appliance only to eat and during oral hygiene.

\section{Resin-reinforced glass ionomer cement bite pads}

Resin-reinforced glass ionomer cement bite pads (Riva Light Cure ${ }^{\circledR}$, Bayswater, Australia) were placed on the occlusal surface of the permanent lower first molars (Fig 2). These devices contained dimensions that were sufficient to promote the disocclusion of all of the anterior teeth, which allowed enough space for the movement of the crossed teeth by tongue pressure.

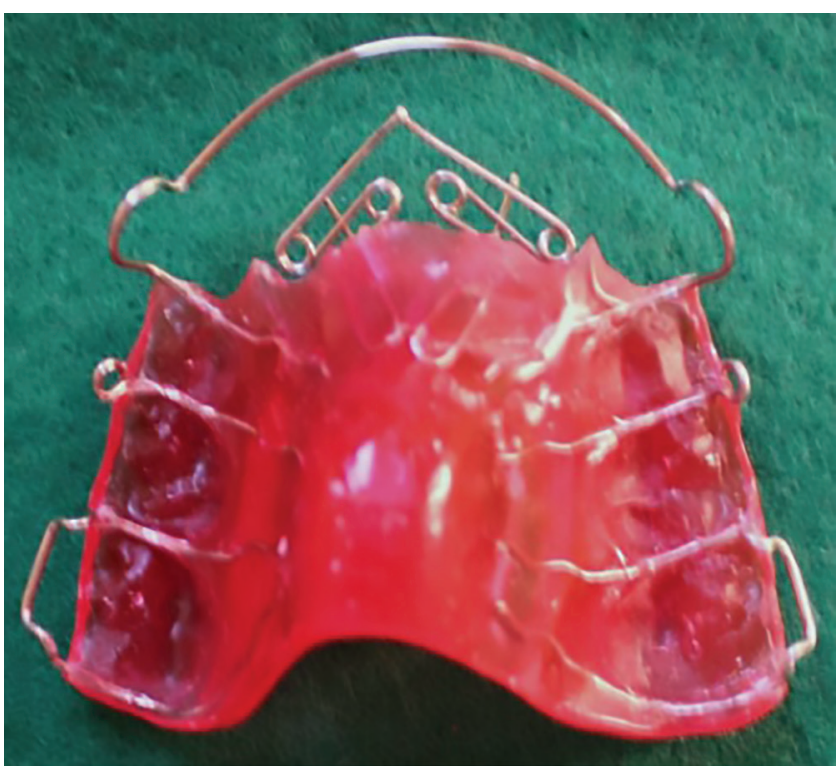

Figure 1 - The upper removable appliance with digital springs. 


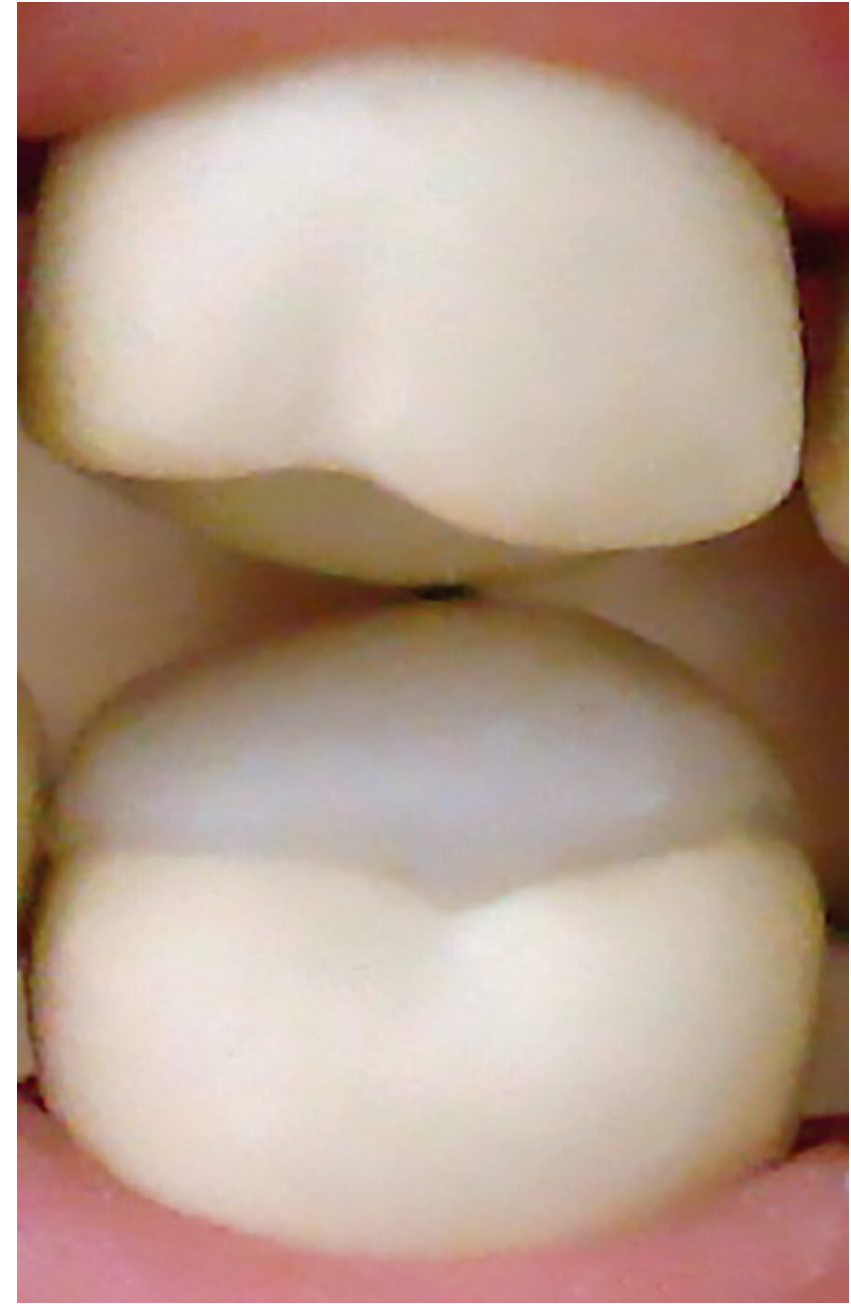

Figure 2 - Glass ionomer cement bite pads

\section{Sample power calculation}

The sample power calculation was carried out by means of the Power and Sample Size Calculation Program (PS, version 3.0, Nashville, Tenn, USA). The overall $\mathrm{CPQ}_{8-10}$ score was the outcome with which the sample power was calculated. For Group 1, the mean difference in the response of matched pairs was 15.53 and the standard deviation of this mean difference was 11.98. For Group 2, the mean difference in the response of matched pairs was 11.73 and the standard deviation of this mean difference was 10.68. The type I error was 0.05 . Thus, the power of the study to identify significant differences between $\mathrm{T}_{1}$ and $\mathrm{T}_{2}$ was $99.4 \%$ for Group 1 and 97.3\% for Group 2.

\section{Orthodontic treatment need assessment}

Children's orthodontic treatment need was assessed using the Dental Aesthetic Index (DAI). The DAI consists of scores for 10 occlusal characteristics. The score of each occlusal characteristic is multiplied by a linear regression coefficient and added together to the constant value of 13 , resulting in the DAI final score. Based on DAI cut-offs, the children were assigned to four groups: slight need of treatment $(\mathrm{DAI} \leq 25)$; elective treatment $(\mathrm{DAI}=26$ to 30$)$; highly desirable treatment (DAI $=31$ to 35$)$, and mandatory treatment (DAI $\geq 36) .{ }^{17}$ Before study's commencement, a training and calibration exercise guaranteed accuracy for the use of DAI.

\section{Monthly family income}

The monthly family income was categorized in terms of the Brazilian minimum wage (BZMW), which was $\mathrm{R} \$ 788.00$ at the time of the study and was established as the sum of monthly income of all economically active members of that family. The children were then categorized as follows: those whose families had a monthly income of $\leq 1$ BZMW; $>1$ BZMW and $\leq 2$ BZMWs; > 2 BZMWs and $\leq 5$ BZMWs and those whose families had a monthly income of $>5$ BZMWs and $\leq 10$ BZMWs.

\section{Data analysis}

Data from both groups were analyzed using the Statistical Package for Social Sciences (SPSS for Windows, version 20.0; SPSS Inc., Chicago, IL, USA). Descriptive statistics were calculated with the aim of providing the sample characteristics. The Shapiro-Wilk test was used to determine the distribution of data and the result showed that the data had non-normal distribution. Inter-group comparisons regarding children's sociodemographic characteristics, orthodontic treatment need and $\mathrm{CPQ}_{8-10}$ scores at $\mathrm{T}_{1}$ were carried out using the Chi-square test and the Mann-Whitney test.

The Wilcoxon signed-rank test was used to assess statistical differences between $T_{1}$ and $T_{2}$ for the subscales and overall $\mathrm{CPQ}_{8-10}$ score. For the overall score, the level of statistical significance was $p<0.05$. The Bonferroni correction was used with the subscales for which the level of statistical significance was $p<0.013$.

Evaluation of the relationship between the type of treatment protocol and the OHRQoL scores at $T_{2}$, 
controlling for confounding variables was carried out by means of the analysis of covariance (ANCOVA). Confounding variables with a $p<0.20$ in the inter-group comparisons were incorporated in the model. Again, the level of significance for the overall score was $p<0.05$ and for the subscales, a $p<0.013$ was considered statistically significant.

\section{RESULTS}

Of the 15 children in Group 1, 11 were male (73.3\%) and 4 were female (26.7\%); the mean age of these children was $9.07 \pm 0.79$ years. Of the 15 children in Group 2, 7 were male (46.7\%) and 8 were female (53.3\%); the mean age was $9.00 \pm 0.84$ years. The socio-demographic characteristics of the participants are presented in Table 1.

Group 1 scores for the FL and EW subscales and the overall $\mathrm{CPQ}_{8-10}$ score were significantly higher in $\mathrm{T}_{1}$ as compared to $\mathrm{T}_{2}(p=0.004, p=0.012$, and $p=0.015$, respectively). There were no significant statistical differences in Group 2 (Table 2).

The results of the ANCOVA showed no significant difference in the subscale and $\mathrm{CPQ}_{8-10}$ overall scores at $T_{2}$ between the two types of treatment protocol (Group 1 and Group 2), after controlling the model for children's measures of quality of life at $\mathrm{T}_{1}$ (Table 3 ).

Table 1 - Children's sociodemographic characteristics, orthodontic treatment needs and quality of life before treatment.

\begin{tabular}{|c|c|c|c|}
\hline & Group 1 & Group 2 & Intergroup comparison ( $p$ value) \\
\hline \multicolumn{4}{|c|}{ Gender of the children } \\
\hline Boys & $11(73.3)$ & $07(46.7)$ & \multirow{2}{*}{$0.264^{\star}$} \\
\hline Girls & $04(26.7)$ & $08(53.3)$ & \\
\hline \multicolumn{4}{|c|}{ Age of the children (years) } \\
\hline 8 & $04(26.6)$ & $05(33.3)$ & \multirow{3}{*}{$0.999 * *$} \\
\hline 9 & $06(40.0)$ & 05 (33.3) & \\
\hline 10 & $05(33.4)$ & $05(33.4)$ & \\
\hline \multicolumn{4}{|c|}{ Orthodontic treatment needs } \\
\hline Slight & $01(06.7)$ & $02(13.3)$ & \multirow{4}{*}{$0.999 * *$} \\
\hline Elective & $05(33.3)$ & $02(13.3)$ & \\
\hline Highly desirable & $04(26.7)$ & $08(53.4)$ & \\
\hline Mandatory & $05(33.3)$ & $03(20.0)$ & \\
\hline \multicolumn{4}{|c|}{ Family income (BZMW) } \\
\hline Up to 1 BZMW & $01(06.7)$ & $01(06.7)$ & \multirow{4}{*}{$0.412^{\star \star}$} \\
\hline From 1 to 2 BZMWs & $07(46.7)$ & $10(66.7)$ & \\
\hline From 2 to 5 BZMWs & $06(40.0)$ & $04(26.7)$ & \\
\hline From 5 to 10 BZMWs & $01(06.7)$ & $00(00.0)$ & \\
\hline \multicolumn{4}{|c|}{$\mathrm{CPQ}_{8-10}\left(\mathrm{~T}_{1}\right)$} \\
\hline $\mathrm{OS}^{1}$ & $7.47(7.00)^{2}$ & $4.40(3.00)^{2}$ & $0.067^{\star \star \star}$ \\
\hline$F L^{1}$ & $6.13(7.00)^{2}$ & $2.40(1.00)^{2}$ & $0.011^{\star \star \star}$ \\
\hline $\mathrm{EW}^{1}$ & $6.33(6.00)^{2}$ & $2.40(0.00)^{2}$ & $0.019 * \star \star$ \\
\hline$S W^{1}$ & $7.80(6.00)^{2}$ & $2.33(1.00)^{2}$ & $0.032^{* * *}$ \\
\hline$O L^{1}$ & $27.87(35.0)^{2}$ & $11.13(7.00)^{2}$ & $0.008^{* * *}$ \\
\hline
\end{tabular}

BZMW = Brazilian monthly wage.

$\mathrm{CPQ}_{8-10}=$ Child Perceptions Questionnaire. $T_{1}=$ before beginning treatment.

$\mathrm{OS}=$ oral symptoms; $\mathrm{FL}$ = functional limitations; $\mathrm{EW}=$ emotional well-being; $\mathrm{SW}=$ social well-being; $\mathrm{OL}=$ overall score.

${ }^{1}$ Analyzed as a continuous variable. ${ }^{2}$ Mean (Median). ${ }^{*}$ Pearson chi-square. ${ }^{* *}$ Linear by linear chi-square. ${ }^{* * *}$ Mann-Whitney test. 
Table 2 - Comparison of the medians and modes of $\mathrm{CPQ}_{8-10}$ subscale and overall scores for the two early treatment protocols of anterior dental crossbite.

\begin{tabular}{|c|c|c|c|c|c|c|}
\hline & $\begin{array}{c}\mathrm{CPQ}_{8-10} \\
\text { Variation }\end{array}$ & $\begin{array}{c}\text { Median } \\
T_{1}\end{array}$ & $\begin{array}{c}\text { Mode } \\
\qquad T_{1}\end{array}$ & $\begin{array}{c}\text { Median } \\
T_{2}\end{array}$ & $\begin{array}{c}\text { Mode } \\
T_{2}\end{array}$ & $\begin{array}{l}p \text { value } \\
T_{1}-T_{2}\end{array}$ \\
\hline \multicolumn{7}{|c|}{ Group 1} \\
\hline OS & $0-20$ & 7.00 & 12 & 4.00 & 6 & $0.032^{*}$ \\
\hline $\mathrm{FL}$ & $0-20$ & 7.00 & 8 & 1.00 & 0 & $0.004^{*}$ \\
\hline EW & $0-20$ & 6.00 & 0 & 1.00 & 0 & $0.012^{*}$ \\
\hline SW & $0-40$ & 6.00 & 0 & 4.00 & 0 & $0.269 *$ \\
\hline $\mathrm{OL}$ & $0-100$ & 35.00 & 36 & 12.00 & 3 & $0.015^{* *}$ \\
\hline \multicolumn{7}{|c|}{ Group 2} \\
\hline OS & $0-20$ & 3.00 & 2 & 5.00 & 8 & $0.441^{*}$ \\
\hline $\mathrm{FL}$ & $0-20$ & 1.00 & 0 & 2.00 & 0 & $0.590 *$ \\
\hline EW & $0-20$ & 0.00 & 0 & 3.00 & 0 & $0.683^{*}$ \\
\hline SW & $0-40$ & 1.00 & 0 & 1.00 & 0 & $0.570 *$ \\
\hline $\mathrm{OL}$ & $0-100$ & 7.00 & 2 & 8.00 & 0 & $0.589 * *$ \\
\hline
\end{tabular}

$C P Q_{8-10}=$ Child Perceptions Questionnaire

$T_{1}=$ before beginning treatment. $T_{2}=12$ months after beginning treatment

$\mathrm{OS}=$ oral symptoms; $\mathrm{FL}=$ functional limitations; $\mathrm{EW}=$ emotional well-being; $\mathrm{SW}=$ social well-being; $\mathrm{OL}=\mathrm{Overall} \mathrm{score}$

* Wilcoxon signed-rank test and Bonferroni correction. Significance level $<0.013$.

** Wilcoxon signed-rank test. Significance level $<0.05$.

Table 3 - ANCOVA models demonstrating contribution of covariates to overall and subscale CPQ ${ }_{8-10} \operatorname{scores}_{\text {at }} T_{2}$.

\begin{tabular}{|c|c|c|c|c|c|c|c|c|c|c|}
\hline & \multicolumn{2}{|c|}{ os } & \multicolumn{2}{|c|}{ FL } & \multicolumn{2}{|c|}{$E W$} & \multicolumn{2}{|c|}{ SW } & \multicolumn{2}{|c|}{ OL } \\
\hline & F statistics & p value* & F statistics & p value* & F statistics & p value* & F statistics & p value* & F statistics & p value ${ }^{* *}$ \\
\hline$C P Q_{8-10}\left(T_{1}\right)$ & 1.5 & 0.231 & 7.3 & 0.012 & 7.24 & 0.012 & 17.98 & 0.001 & 7.49 & 0.011 \\
\hline $\begin{array}{c}\text { Treatment } \\
\text { protocol }\end{array}$ & 0.96 & 0.335 & 0.02 & 0.9 & 0.65 & 0.424 & 0.36 & 0.553 & 0.76 & 0.39 \\
\hline
\end{tabular}

$\mathrm{CPQ}_{8-10}=$ Child Perceptions Questionnaire

$T_{1}=$ before beginning treatment; $T_{2}=12$ months after beginning treatment

$\mathrm{OS}=$ oral symptoms; $\mathrm{FL}=$ functional limitations; $\mathrm{EW}=$ emotional well-being; $\mathrm{SW}=$ social well-being; $\mathrm{OL}=\mathrm{Overall}$ score

*Significance level $<0.013$. **Significance level $<0.05$.

\section{DISCUSSION}

The results of this study confirmed that no statistical difference was found in the OS, FL, EW and SW subscales as well as in the overall $\mathrm{CPQ}_{8-10}$ score between children wearing an upper removable appliance with digital springs and children who were treated with resin-reinforced glass ionomer cement bite pads on the lower first molars. The covariate that contributed most for individuals' OHRQoL at $\mathrm{T}_{2}$ was the measures of quality of life at $\mathrm{T}_{1}$ in the FL, EW and $\mathrm{SW}$ subscales as well as in the overall $\mathrm{CPQ}_{8-10}$ score.

Within interceptive orthodontics, recent studies have shown the positive effect of orthodontic therapy on the OHRQoL of treated patients. ${ }^{12,18}$ It is impor- tant to understand that an improved function is not the only reason why many individuals seek treatment. ${ }^{19,20}$ The effects of malocclusion on emotional and social well-being are also important justifications for seeking orthodontic treatment, ${ }^{21}$ and these are the motivations that subjective indices, such as the $\mathrm{CPQ}_{8-10}$, also assess. OHRQoL has been considered a multidimensional construct, in regards to the frequency of the impact that oral conditions may have on physical aspects, such as oral symptoms and functional limitations. This construct also concerns the effects of oral outcomes on individuals' psychosocial aspects. ${ }^{22}$ It has been recognized that malocclusion has a negative impact on children's and adolescents' quality of life, mostly on emotional and 
social well-beings ${ }^{23}$ and orthodontic treatment, on the other hand, improves OHRQoL with positive repercussions on functioning ${ }^{18}$ and self-esteem. ${ }^{12}$

OHRQoL assessment becomes relevant in the participants' age group, especially with regard to anterior dental crossbite, given that correction in mixed dentition are recommended to avoid compromising the dentofacial condition, which could result in the development of periodontal issues due to traumatic occlusion ${ }^{24}$ or a skeletal Class III malocclusion. ${ }^{89}$ These findings may indicate the need for the orthodontist to prioritize the early correction of this irregularity ${ }^{25}$ and any other irregularities, such as the presence of crowding in the anterior region, ${ }^{26}$ to improve the patients' perception in regard to their dental appearance. This work highlights the importance of diagnosis and early intervention for anterior dental crossbite using orthodontic devices that seem to correct this malocclusion quickly and effectively, with minimal discomfort to the child. ${ }^{27}$

This study has limitations that need to be acknowledged. The first regards the income of the families. Most participants belonged to families with monthly income of less than 5 BZMWs. The present evaluation would have benefited of a more equalized sample in terms of socioeconomic characteristics. Although some factors that could influence the results were controlled, such as having treatments performed by only one practitioner, other factors were not controlled, such as differences (intragroups) regarding the severity of malocclusion. ${ }^{28}$ Moreover, children in the second assessment did not demonstrate the same stage of correction in their anterior dental crossbite.

A systematic review ${ }^{29}$ on the treatment of anterior dental crossbite showed that most of the articles published about therapy protocols for this malocclusion are case reports. Moreover, none of the included studies evaluated patients' perceptions and the impact of treatment on their OHRQoL. There are several fixed or removable devices used to correct anterior dental crossbite. The choice of a particular type of treatment depends on a close examination of various factors, such as the severity of malocclusion, the patient's tolerance of discomfort caused by the treatment, and the professional skill of the orthodontist performing the treatment. Therefore, future research should be conducted addressing the impact of different early treatment protocols for anterior dental crossbite. Evidence-based dentistry, in the last 20 years, has been understood as the standard for oral health care worldwide. ${ }^{30}$ Clinicians should consider in their clinical routine both clinical experience and the best available evidence. However, awareness of patients' needs and preferences is also an important component of orthodontic practice. The psychosocial characteristics of individuals along with their perceptions, expectations and values need to be taken into account when practitioners are providing orthodontic treatment. ${ }^{31}$

\section{CONCLUSION}

While the quality of life of children undergoing treatment with upper removable appliance with digital springs improved, no change was observed in the quality of life of children submitted to treatment with resinreinforced glass ionomer cement bite pads. This difference regarding the impact on OHRQoL, however, is unrelated to the protocol used. 
1. Sischo L, Broder HL. Oral health-related quality of life: what, why, how and future implications. J Dent Res. 2011 Nov;90(11):1264-70.

2. Martins-Júnior PA, Oliveira M, Marques LS, Ramos-Jorge ML. Untreated dental caries: impact on quality of life of children of low socioeconomic status. Pediatr Dent. 2012 May-June;34(3):49-52.

3. Ukra A, Foster Page LA, Thomson WM, Farella M, Tawse Smith A, Beck V. Impact of malocclusion on quality of life among New Zealand adolescents. N Z Dent J. 2013 Mar;109(1):18-23.

4. Wallander JL, Schmitt M, Koot HM. Quality of life measurement in children and adolescents: issues, instruments, and applications. J Clin Psychol. 2001 Apr:57(4):571-85

5. Jirgensone I, Liepa A, Abeltins A. Anterior crossbite correction in primary and mixed dentition with removable inclined plane (Bruckl appliance). Stomatologija. 2008:10(4):140-4

6. Valentine F, Howitt JW. Implication of early anterior crossbite correction. ASDC J Dent Child. 1970 Sept-Out;37(5):420-7.

7. Vadiakas G, Viazis AD. Anterior crossbite correction in the early deciduous dentition. Am J Orthod Dentofacial Orthop. 1992 Aug;102(2):160-2.

8. Karaiskos N, Wiltshire WA, Odlum O, Brothwell D, Hassard TH. Preventive and interceptive orthodontic treatment needs of an inner-city group of 6- and 9-yearold Canadian children. J Can Dent Assoc. 2005 Oct;71(9):649.

9. Schopf P. Indication for and frequency of early orthodontic therapy or interceptive measures. J Orofac Orthop. 2003 May;64(3):186-200.

10. Zhang M, McGrath C, Hagg U. Changes in oral health-related quality of life during fixed orthodontic appliance therapy. Am J Orthod Dentofacial Orthop. 2008 Jan;133(1):25-9.

11. Abreu LG, Melgaço CA, Lages EM, Abreu MH, Paiva SM. Effect of year one orthodontic treatment on the quality of life of adolescents, assessed by the short form of the Child Perceptions Questionnaire. Eur Arch Paediatric Dent. 2014 Dec:15(6):435-41

12. Souki BQ, Figueiredo DS, Lima IL, Oliveira DD, Miguel JA. Two-phase orthodontic treatment of a complex malocclusion: giving up efficiency in favor of effectiveness, quality of life, and functional rehabilitation? Am J Orthod Dentofacial Orthop. 2013 Apr;143(4):547-58.

13. Abraham KK, James AR, Thenumkal E, Emmatty T. Correction of anterior crossbite using modified transparente algners: An esthetic approach. Contemp Clin Dent 2016 Jul-Sept;7(3):394-7.

14. Piassi E, Antunes LS, Andrade MR, Antunes LA. Quality of life following orthodontic therapy for anterior crossbite: report of cases in twin boys. Case Rep Dent. 2016:2016:3685693

15. Jokovic A, Locker D, Tompson B, Guyatt G. Questionnaire for measuring oral health-related quality of life in eight- to ten-year-old children. Pediatr Dent. 2004 Nov-Dec;26(6):512-8
16. Martins MT, Ferreira FM, Oliveira AC, Paiva SM, Vale MP, Allison PJ, et al Preliminary validation of the Brazilian version of the Child Perceptions Questionnaire 8-10. Eur J Paediatr Dent. 2009 Sept;10(3):135-40.

17. Jenny J, Cons NC. Establishing malocclusion severity levels on the Dental Aesthetic Index (DAl) scale. Aust Dent J. 1996 Feb;41(1):43-6.

18. Seehra J, Newton JT, Dibiase AT. Interceptive orthodontic treatment in bullied adolescents and its impact on self-esteem and oral-health-related quality of life. Eur J Orthod. 2013 Oct; 35(5):615-21

19. Bernabé E, Sheiham A, Tsakos G, Messias de Oliveira C. The impact of orthodontic treatment on the quality of life in adolescents: a case-control study Eur J Orthod. 2008 Oct; 30(5):515-20

20. Liu Z, McGrath C, Hägg U. The impact of malocclusion/orthodontic treatment need on the quality of life: a systematic review. Angle Orthod. 2009 May:79(3):585-91.

21. Wedrychowska-Szulc B, Syrynska M. Patient and parent motivation for orthodontic treatment--a questionnaire study. Eur J Orthod. 2010 Aug;32(4):44752

22. Cella DF. Quality of life: concepts and definition. J Pain Symptom Manage. 1994 Apr:9(3):186-92

23. Dimberg $L$, Arnrup K, Bondemark $L$. The impact of malocclusion on the quality of life among children and adolescents: a systematic review of quantitative studies. Eur J Orthod. 2015 June;37(3):238-47.

24. Eismann D, Prusas R. Periodontal findings before and after orthodontic therapy in cases of incisor cross-bite. Eur J Orthod. 1990 Aug:12(3):281-3.

25. Nagarajan S, Pushpanjali K. The relationship of malocclusion as assessed by the Dental Aesthetic Index (DAl) with perceptions of aesthetics, function, speech and treatment needs among 14- to 15-year-old schoolchildren of Bangalore, India. Oral Health Prev Dent. 2010;8(3):221-8

26. Marques LS, Ramos-Jorge ML, Paiva SM, Pordeus IA. Malocclusion: esthetic impact and quality of life among Brazilian schoolchildren. Am J Orthod Dentofacial Orthop. 2006 Mar:129(3):424-7.

27. Proffitt WR. The timing of early treatment: an overview. Am J Orthod Dentofacial Orthop. 2006 Apr;129(4 Suppl):S47-9.

28. Joury E, Marcenes W, Johal A. The role of psychosocial factors in predicting orthodontic treatment outcome at the end of 1 year of active treatment. Eur J Orthod. 2013 Apr;35(2):205-15.

29. Borrie F, Bearn D. Early correction of anterior crossbites: a systematic review. J Orthod. 2011 Sept;38(3):175-84.

30. Richards D, Lawrence A. Evidence-based practice. Br Dent J. 1996 Sept;181(5):165.

31. Yao J, Li DD, Yang YQ, MCGrath CP, Mattheos N. What are the patients expectations of orthodontic treatment: a systematic review. BMC Oral Health. 2016 Feb;16:19. 